\title{
Goitre decline in Italy and contribution of the silent and active prophylaxis
}

\author{
Venanzio Vella* \\ Epidemiology Unit, Department of Health, Natalia Building, South Tower, 330 LongMarket Street, Pietermaritzburg, 3200, South Africa \\ (Received 10 January 2005 - Revised 13 May 2005 - Accepted 20 June 2005)
}

\begin{abstract}
Goitre has been declining in Italy since the 1970s and because active prophylaxis (AP) has been very limited, it has been suggested that in most places the decline was due to silent prophylaxis (SP). SP is related to the natural increase in iodine intake because of higher consumption of iodine-rich products associated with socioeconomic development. The hypothesis tested in the present study is that SP has increased iodine intake in Italy with subsequent reduction of goitre and that such changes can be quantified. The analysis is based on surveys carried out between the 1970s and the 1990s where goitre and urinary iodine, a proxy of consumption, were measured in schoolchildren. The contribution of the SP can be quantified in an annual increase in urinary iodine excretion between $2 \cdot 1$ and $4 \mu \mathrm{g} / \mathrm{l}$, and an annual decline in goitre prevalence between $2 \cdot 1$ and $3.6 \%$. In the few areas with AP, there was an annual increase in urinary iodine between 6.5 and $13.1 \mu \mathrm{g} / \mathrm{l}$, while the average annual decline of goitre was between 4.4 and $10 \%$. The present results could be used by policy-makers to predict the future trends in the excretion of urinary iodine and prevalence of goitre in Italy with and without AP. AP is about three times faster than SP in increasing iodine intake, but policy-makers should estimate the incremental cost-effectiveness of AP net of the iodine increase already occurring naturally with the SP.
\end{abstract}

Goitre: Iodine: Silent prophylaxis: Active prophylaxis: Cost-effectiveness: Italy

Iodine deficiency has been always rampant in Italy. Several surveys (Aghini-Lombardi et al. 1998) have shown high rates of goitre and low urinary secretion of iodine, a proxy of iodine intake. These surveys have been mostly descriptive and no multivariate analysis has been attempted to utilize more efficiently all the available information.

Active prophylaxis (AP) has been very limited. In Italy, iodized salt is consumed by a small minority, as it has been estimated that less than $3 \%$ of all salt consumed is iodized (Aghini-Lombardi \& Antonangeli, 1998). AP, defined in this analysis as the proactive promotion of iodized salt or the iodization of water supplies has been carried out in limited areas, namely in the localities of Vagli (Aghini-Lombardi et al. 1995), Garfagnana (Maccherini et al. 1998) and Valtiberina (Antonangeli et al. 1998) in Tuscany; and in Bolzano (Franzellin, 1998) in the Alto Adige region since the early 1980s; while in Troina, north-east Sicily, AP was carried out between the late 1970s and 1987 (Regalbuto et al. 1996).

It has been suggested that the decline of goitre in areas without AP was the result of silent prophylaxis (SP). Regalbuto et al. (1998) observed that goitre has declined in Sicily without specific interventions, as a result of 'silent prophylaxis due to change in environmental conditions and life styles'. Other researchers (Vermiglio et al. 1989) have suggested that SP is the result of socioeconomic development, leading to increased consumption of iodine-rich products coming from outside the iodine-deficient localities. Delange et al. (2000) suggested that although SP has partially corrected iodine deficiency in Western Europe, AP is still required. However, no quantification of SP has been attempted and even if SP may not be sufficient to eliminate iodine deficiency completely, its contribution needs to be quantified to estimate the net benefit of AP over and above SP.

The quantification of SP would provide a basis for estimating the trends expected in the future, with and without AP, and the incremental benefits to be expected from AP. Like any programme, AP is not exempted from the policy issue related to the assignment of limited resources according to the incremental cost-effectiveness of interventions. Therefore, policy-makers need to estimate the costs and the incremental benefits of AP over and above the natural increase in iodine intake caused by the SP.

The present analysis has the objective of quantifying the contribution of SP in Italy between the 1970s and the 1990s. The analysis aims to reply to critical questions related to the net benefit of AP against iodine deficiency in Italy and in other countries with similar socioeconomic conditions. Such questions include: What is the relationship between urinary excretion of iodine and goitre prevalence? What has been the role of SP in increasing iodine excretion and in decreasing goitre prevalence? What is the net advantage of the AP versus the SP?

\begin{abstract}
Methods
All published articles related to surveys on iodine deficiency and goitre carried out in Italy between 1970 and 1999 were traced through Medline and were assessed. The surveys which were carried out according to the WHO criteria (Report of the Subcommittee for the Study of Endemic Goitre, 1985) on palpation of goitre and measurement of urinary iodine as $24 \mathrm{~h}$ excretion in $\mu \mathrm{g} / \mathrm{l}$, and which had estimates on both goitre and urinary iodine were
\end{abstract}


accepted. The altitude, latitude and distance from the sea of the localities were obtained from the Istituto Nazionale di Statistica (1990).

There was a first group of sixty localities that were surveyed only once, while a second group of nine localities were surveyed more than once and provided longitudinal data. The sixty localities, scattered across the country between Sicily and the Austrian border, were located between 0 and $190 \mathrm{~km}$ from the seaside and their altitude varied between 0 and $1000 \mathrm{~m}$ above sea level. These localities, which were surveyed across the whole country between the 1970s and the 1990s, should provide a fairly representative picture of the relationship between urinary iodine and goitre prevalence in Italy.

The data were entered into a regression model containing $\mu \mathrm{g} / \mathrm{l}$ urinary iodine against the goitre prevalence as dependent. The objective was to predict the increase of $\mu \mathrm{g} / \mathrm{l}$ urinary iodine required to decrease goitre prevalence. The slope predicted by the model based on the sixty localities covered only once through cross-sectional surveys was compared with the real trends measured in the nine localities that were surveyed more than once. This comparison had the objective of assessing if the decline experienced in the nine localities differed substantially from the rest of the country. Of the nine localities surveyed more than once, Valtiberina, Vagli, Garfagnana and Bolzano have received uninterrupted AP since the early 1980s. In the remaining communities, which did not receive AP, the increase in urinary iodine was considered due to SP.

\section{Results}

The details of the population covered by the studies are in Tables 1 and 2. Table 1 shows the first group of sixty localities that were surveyed only once, between the 1970s and the 1990s. Table 2 provides the information on the second group of nine localities with longitudinal data. Most of the studies, which are shown in Tables 1 and 2, were based on schoolchildren aged between 6 and 14 years, who were examined by people trained in detecting palpable goitre. In the sixty localities surveyed once, goitre varied between 0 and $73 \%$, while the mean/median urinary iodine varied between 35 and $224 \mu \mathrm{g} / \mathrm{l}$.

The first group of sixty localities were included in the analysis even if some results of the urinary excretion in $\mu \mathrm{g} / \mathrm{l}$ were reported as mean and others as median. To check if this would have caused problems, two regression models, containing goitre as dependent and urinary iodine as independent, were carried out. The first regression model in Table 3 included the localities with the mean $\mu \mathrm{g}$ urinary iodine and the second regression model in Table 4 included the localities with the median $\mu \mathrm{g}$ urinary iodine. Because the two regression models containing the mean and the median urinary iodine produced almost identical coefficients, with very similar standard errors and $95 \%$ confidence intervals, the sixty estimates were used in the same multiple regression model.

The relationship between urinary iodine and goitre prevalence was better fitted through a quadratic model. When the data from the sixty communities were entered into a regression model containing goitre as dependent and iodine as independent, the change from linear to quadratic model increased the $R^{2}$ from 50 to $61 \%$. This suggested that for a given increase in urinary iodine, goitre declined faster when prevalence was high.
As shown in Fig. 1, the slope of the curve between urinary iodine and goitre is steeper when the prevalence of goitre is very high, becomes less steep at intermediate prevalence of goitre and reaches a plateau when the prevalence of goitre is low. A stepwise introduction of other variables to improve the quadratic model included latitude, altitude and distance from the sea (in $\mathrm{km}$ ) of the localities. Only distance from the sea increased significantly the $R^{2}$ to $65 \%$ and it was kept in the final model shown in Table 5 .

The quadratic model confirms the known relationship between the iodine intake and prevalence of goitre, but it provides the extra information of a stronger effect of iodine at higher levels of prevalence rates. It is known that high levels of urinary iodine, which is a reflection of iodine consumption, are associated with low prevalence of goitre and vice versa. However, the quadratic model is value added because it shows that for a given increase in urinary iodine there will be a more striking effect in localities with a high prevalence of goitre.

The relationship was operationalized in Table 6. The coefficients predicted by the quadratic model were used to quantify the relationship between iodine increase and goitre decline. In Table 6, the first to the last row represent respectively, the concentration in urinary iodine, the relative prevalence of goitre predicted by the model, the decline in the prevalence of goitre expected if urinary iodine increases up to the value indicated in the next column, the decline in goitre prevalence expected for each $\mu \mathrm{g}$ increase of urinary iodine and the increase in urinary iodine required for goitre prevalence to decline by $1 \%$.

For example, the first two rows and the first two columns of Table 6 indicate respectively, that at 10 and $20 \mu \mathrm{g} / \mathrm{l}$ urinary iodine, the prevalence of goitre predicted by the model is 63.5 and $55.4 \%$ respectively. Therefore, the increase from 10 to $20 \mu \mathrm{g} / \mathrm{l}$ in urinary iodine is expected to be followed by a decline of $-8.1 \%$ in goitre prevalence $(63.5 \%$ to $55.4 \%$ ), as indicated in the third row of the first column. This decline of $8.1 \%$ of goitre prevalence divided by the increase in $10 \mu \mathrm{g}$ in urinary iodine (from 10 to 20 ) is equivalent to an average $0.8 \%$ decline in goitre prevalence for each $\mu \mathrm{g}$ increase in urinary iodine, as indicated in the fourth row of the first column. Another way to put it is that when goitre is between 63.5 and $55.4 \%$, each increase of $1.2 \mu \mathrm{g} / \mathrm{l}$ urinary iodine is associated with $1 \%$ decline in goitre prevalence, as indicated in the last row of the first column.

As indicated by the second and the last row of Table 6, when goitre prevalence declines, urinary iodine has to increase gradually from slightly more than 1 to $2 \mu \mathrm{g} / \mathrm{l}$ to produce $1 \%$ decline in goitre prevalence. This is evident in the second and last row of Table 6 , showing that when prevalence is higher than $60 \%$ each increase of $1.2 \mu \mathrm{g}$ urinary iodine is sufficient to bring down goitre prevalence by $1 \%$. When prevalence of goitre is between 55 and $40 \%$, urinary iodine has to increase by $1.3-1.4 \mu \mathrm{g} / \mathrm{l}$ to produce the same decline of $1 \%$ of goitre. The amount of urinary iodine required to produce $1 \%$ decline increases further when prevalence of goitre is lower.

Figs. 2 and 3 show the real trends in the nine localities surveyed more than once. The steeper increases in urinary iodine in Bolzano, Vagli, Valtiberina and Garfagnana were due to AP which was carried out since the early 1980s. Troina followed the same steep increase in urinary iodine untill the middle of the 1980s, when AP was discontinued. After the mid-1980s the pace in the increase in urinary iodine in Troina was similar to 
that of the localities without AP. Fig. 3 shows that goitre declined faster in the localities where iodine increase was steeper.

The slope of the relationship between the increase in urinary iodine and the decline in goitre prevalence in the nine localities that were surveyed more than once was very similar to the slope predicted by the quadratic model based on the sixty localities which were surveyed across the countries. In Fig. 4, the average annual increase in urinary iodine is put against the

Table 1. First group of sixty localities which were surveyed once

\begin{tabular}{|c|c|c|c|c|c|}
\hline Year & Area & $n^{\star}$ & Goitre prevalence (\%) & Urinary iodine $(\mu \mathrm{g} / \mathrm{l})$ & lodine measure \\
\hline 1994 & Catania & 1253 & 1 & 224 & Median \\
\hline 1977 & Messina & 608 & 7 & 76 & Mean \\
\hline 1977 & Siracusa & 947 & 0 & 83 & Mean \\
\hline 1977 & Nicosia & 1642 & 39 & 39 & Mean \\
\hline 1992 & Calabria area 3 & 4879 & 44 & 44 & Mean \\
\hline 1992 & Calabria area 4 & 2581 & 41 & 55 & Mean \\
\hline 1992 & Calabria area 7 & 645 & 23 & 70 & Mean \\
\hline 1992 & Calabria area 8 & 747 & 40 & 60 & Mean \\
\hline 1992 & Calabria area 9 & 1998 & 16 & 89 & Mean \\
\hline 1992 & Calabria area 14 & 831 & 15 & 90 & Mean \\
\hline 1991 & Potenza & NA & 21 & 55 & Median \\
\hline 1994 & Nuoro & 2050 & 29 & 89 & Mean \\
\hline 1994 & Cagliari (province) & 2885 & 18 & 97 & Mean \\
\hline 1991 & Cagliari (urban) & NA & 12 & 84 & Mean \\
\hline 1994 & Oristano & 1854 & 35 & 54 & Mean \\
\hline 1994 & Sassari & 1299 & 17 & 84 & Mean \\
\hline 1990 & Benevento & NA & 73 & 37 & Mean \\
\hline 1994 & Napoli & 34 & 15 & 102 & Mean \\
\hline 1994 & Tufo & 51 & 47 & 63 & Median \\
\hline 1994 & Chiance & 59 & 49 & 66 & Median \\
\hline 1994 & Flumeri & 270 & 40 & 47 & Median \\
\hline 1994 & Pietradefusi & 139 & 40 & 49 & Median \\
\hline 1994 & Torrele Nocelle & 109 & 51 & 45 & Median \\
\hline 1994 & Venticano & 190 & 54 & 42 & Median \\
\hline 1994 & Villanova & 127 & 52 & 52 & Median \\
\hline 1990 & Pesaro (province) & NA & 27 & 88 & Median \\
\hline 1990 & Pesaro (urban) & NA & 7 & 133 & Median \\
\hline 1990 & Ancona & NA & 20 & 96 & Median \\
\hline 1990 & Ascoli Piceno & NA & 15 & 90 & Median \\
\hline 1990 & Macerata & NA & 20 & 75 & Median \\
\hline 1991 & Serchio & 719 & 9 & 80 & Mean \\
\hline 1991 & Marina di Pisa & 106 & 3 & 173 & Mean \\
\hline 1981 & Alta Lunigiana & NA & 64 & 38 & Mean \\
\hline 1982 & Bossa Lunigiana & NA & 43 & 35 & Mean \\
\hline 1983 & Colline Pisane & NA & 22 & 36 & Mean \\
\hline 1986 & Val di Nievole & NA & 48 & 49 & Mean \\
\hline 1988 & Pistoia Appennino & NA & 41 & 55 & Mean \\
\hline 1991 & Firenze & NA & 38 & 71 & Mean \\
\hline 1991 & Lucca & NA & 8 & 64 & Median \\
\hline 1993 & Arezzo & NA & 10 & 91 & Median \\
\hline 1982 & Massa Carrara & NA & 43 & 37 & Median \\
\hline 1992 & Grosseto & NA & 6 & 75 & Median \\
\hline 1990 & Varsi & NA & 54 & 72 & Mean \\
\hline 1990 & Reggio Emilia & 1020 & 26 & 108 & Mean \\
\hline 1990 & Bologna (urban) & 175 & 6 & 159 & Median \\
\hline 1990 & Bologna & NA & 6 & 107 & Mean \\
\hline 1985 & Forli & NA & 44 & 58 & Mean \\
\hline 1992 & Padova & NA & 16 & 118 & Mean \\
\hline 1993 & Veneto Plain & 1928 & 7 & 148 & Mean \\
\hline 1993 & Belluno & 990 & 6 & 155 & Mean \\
\hline 1993 & Treviso & 1232 & 12 & 130 & Mean \\
\hline 1993 & Vicenza & 1289 & 12 & 130 & Mean \\
\hline 1992 & Rovigo (urban) & NA & 8 & 90 & Mean \\
\hline 1992 & Venezia (urban) & NA & 2 & 223 & Mean \\
\hline NA & Altavilla & NA & 32 & 62 & Median \\
\hline NA & Colline Metallifere & NA & 5 & 85 & Median \\
\hline NA & Dentacane & NA & 29 & 62 & Median \\
\hline NA & Castel d'Aiano & NA & 13 & 123 & Median \\
\hline NA & Gaggio montano & NA & 19 & 116 & Median \\
\hline NA & Pietracola & NA & 24 & 80 & Median \\
\hline
\end{tabular}

NA, not available.

${ }^{*}$ Most of the studies were based on schoolchildren aged 6-14 years. 
Table 2. Second group of nine localities which were sampled more than once

\begin{tabular}{|c|c|c|c|c|c|c|}
\hline Year & Area & $n^{\star}$ & Goitre prevalence (\%) & Urinary iodine $(\mu \mathrm{g} / \mathrm{l})$ & AP & lodine measure \\
\hline 1977 & Troina & 1200 & 52 & 41 & Yes & Median \\
\hline 1983 & & 1200 & 6 & 86 & & Median \\
\hline 1994 & & 1200 & 8 & 106 & & Median \\
\hline 1977 & Maniaci & 218 & 67 & 19 & No & Median \\
\hline 1983 & & 218 & 47 & 25 & & Median \\
\hline 1994 & & 218 & 26 & 68 & & Median \\
\hline 1977 & Santangelo & 439 & 49 & 26 & No & Mean \\
\hline 1987 & & 439 & 28 & 48 & & Mean \\
\hline 1977 & Castel Umberto & 348 & 80 & 22 & No & Mean \\
\hline 1987 & & NA & 44 & 49 & & Mean \\
\hline 1977 & Sinagra & NA & 62 & 26 & No & Mean \\
\hline 1987 & & NA & 33 & 67 & & Mean \\
\hline 1981 & Vagli & 496 & 58 & 47 & Yes & Mean \\
\hline 1991 & & 307 & 8 & 130 & & Mean \\
\hline 1985 & Valtiberina & NA & 52 & 39 & Yes & Mean \\
\hline 1993 & & NA & 17 & 91 & & Mean \\
\hline 1984 & Garfagnana & 142 & 78 & 55 & Yes & Mean \\
\hline 1991 & & NA & 8 & 147 & & Mean \\
\hline 1982 & Bolzano & 49 & 24 & 10 & Yes & Mean \\
\hline 1990 & & 917 & 2 & 137 & & Mean \\
\hline 1997 & & 189 & NA & 177 & & Mean \\
\hline
\end{tabular}

AP, active prophylaxis; NA, not available.

*Most of the studies were based on schoolchildren aged 6-14 years.

average annual decline in goitre prevalence which occurred in the nine localities. The numbers besides the localities represent the average increase in $\mu \mathrm{g}$ urinary iodine associated with $1 \%$ decline in the prevalence of goitre. For example, Bolzano had an average annual increase of slightly more than $11 \mu \mathrm{g} / \mathrm{l}$ urinary iodine, an average annual decline of $5 \%$ in goitre prevalence, which is equivalent to $2.27 \mu \mathrm{g}$ increase of urinary iodine per $1 \%$ decline in goitre. Almost in all the localities, urinary iodine had to increase between 1 and $2 \mu \mathrm{g} / \mathrm{l}$ for goitre to decline by $1 \%$. The faster slope was in Castel Umberto where an average increase of less than $1 \mu \mathrm{g} / \mathrm{l}$ urinary iodine was associated with an average decline of $1 \%$ in the prevalence of goitre. The reason for the faster decline in Castel Umberto was related to its initial very high prevalence of goitre, which was $80 \%$. This is in line with the steeper relationship between iodine increase and goitre decline predicted by the quadratic model.

The present findings suggest that what happened in the nine localities was similar to what happened across the country. The quadratic model predicted that in localities where prevalence of goitre was very high, as in the case of Castel Umberto, an increase of about $1 \mu \mathrm{g}$ urinary iodine was associated with a $1 \%$ prevalence decline in goitre. For the other eight localities with

Table 3. Regression with mean urinary iodine (dependent variable: goitre prevalence)

\begin{tabular}{|c|c|c|c|c|c|}
\hline \multirow[b]{2}{*}{ Model } & \multicolumn{2}{|c|}{$\begin{array}{l}\text { Unstandardized } \\
\text { coefficients }\end{array}$} & \multirow{2}{*}{$\frac{\text { Standardized coefficient }}{\beta}$} & \multirow[b]{2}{*}{$t$} & \multirow[b]{2}{*}{ Significance } \\
\hline & $B$ & SE & & & \\
\hline (Constant) & $74 \cdot 391$ & $8 \cdot 658$ & & 8.592 & 0.000 \\
\hline Mean urinary iodine $(\mu \mathrm{g} / \mathrm{l})$ & -0.937 & 0.174 & $-2 \cdot 117$ & $-5 \cdot 377$ & 0.000 \\
\hline Distance from the sea $(\mathrm{km})$ & 0.124 & 0.050 & 0.255 & $2 \cdot 453$ & 0.020 \\
\hline IODSQUAR & 0.003 & 0.001 & 1.470 & $3 \cdot 718$ & 0.001 \\
\hline
\end{tabular}

IODSQUAR, urinary iodine squared.

Table 4. Regression with median urinary iodine (dependent variable: goitre prevalence)

\begin{tabular}{|c|c|c|c|c|c|}
\hline \multirow[b]{2}{*}{ Model } & \multicolumn{2}{|c|}{$\begin{array}{l}\text { Unstandardized } \\
\text { coefficients }\end{array}$} & \multirow{2}{*}{$\frac{\text { Standardized coefficient }}{\beta}$} & \multirow[b]{2}{*}{$t$} & \multirow[b]{2}{*}{ Significance } \\
\hline & $B$ & SE & & & \\
\hline (Constant) & $69 \cdot 075$ & $11 \cdot 701$ & & 5.903 & 0.000 \\
\hline Mean urinary iodine $(\mu \mathrm{g} / \mathrm{l})$ & -0.822 & 0.213 & $-2 \cdot 020$ & -3.859 & 0.001 \\
\hline Distance from the sea $(\mathrm{km})$ & 0.064 & 0.045 & 0.188 & 1.404 & 0.175 \\
\hline IODSQUAR & 0.002 & 0.001 & $1 \cdot 410$ & 2.698 & 0.013 \\
\hline
\end{tabular}

IODSQUAR, urinary iodine squared. 


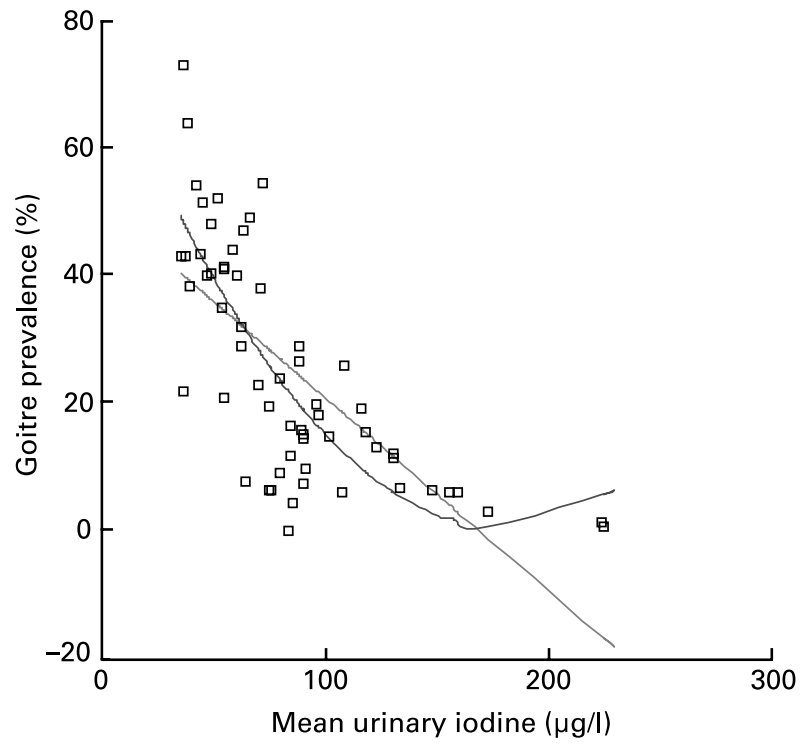

Fig. 1. Linear ( - ) and quadratic ( - ) model containing the observed data ( $\square$ ) from the sixty localities (dependent variable: goitre prevalence).

longitudinal data, an increase in urinary iodine between 1 and $2 \mu \mathrm{g} / \mathrm{l}$ was accompanied with an average goitre decline of $1 \%$, as predicted by the quadratic model.

Another piece of information represented in Fig. 4 is that Bolzano, Vagli, Valtiberina and Garfagnana are distant from the rest. This is due to the faster annual increase in the excretion of urinary iodine in these localities because they had AP. In these localities receiving $\mathrm{AP}$, the annual increase in urinary iodine was between 6.5 and $13.1 \mu \mathrm{g} / \mathrm{l}$ and the annual decline in goitre prevalence was between 4.4 and $10 \%$. In the other localities without AP the annual increase in urinary iodine was between $2 \cdot 1$ and $4 \mu \mathrm{g} / \mathrm{l}$ and the decline in goitre prevalence was between $2 \cdot 1$ and $3.6 \%$, which can be considered due to the SP.

\section{Discussion}

The present analysis has efficiently used published data to measure a 'natural experiment'. Tens of articles have been published on surveys which were carried out across Italy to measure the relationship between goitre and iodine deficiency. Although these papers were very informative, they were mainly descriptive. This has been the first attempt to provide a more comprehensive overview of iodine deficiency in Italy and to measure the effect of SP.

The slope of the trends between iodine increase and goitre decline experienced in the second group of nine localities was very similar to the predictions of the quadratic model. Although the nine communities were not randomly selected to represent the whole country, their trends confirm those predicted by the quadratic model based on the sixty localities that were scattered between Sicily and the Austrian border. Therefore, it is likely that the nine localities provide a good representation of the relationship between urinary iodine increase and goitre decline across the country.

Real trends show that SP has been associated with an increase in urinary iodine excretion and a decline in goitre prevalence. The average annual increase in urinary iodine excretion in localities with SP was between $2 \cdot 1$ and $4 \mu \mathrm{g} / \mathrm{l}$, while the annual decline in goitre prevalence was between $2 \cdot 1$ and $3.6 \%$. The fact that the areas that did not receive any specific intervention have recorded an increase in urinary iodine confirms the existence of SP. Even if this 'natural experiment' cannot have the same evidence of a randomized community trial, the causal inference between the increase in urinary iodine and the decline in goitre associated with SP is clear. This causal inference is suggested by the concordance between the magnitude of the changes experienced by the localities under SP and AP.

Although AP is faster in increasing urinary iodine, its benefits should be estimated at the net of those due to SP. AP requires a certain cost that is directly proportional to the efforts involved in ensuring that AP is efficiently carried out and that consumers decide to buy iodized salt instead of non-iodized salt. In times of evidence-based medicine and rationing, the incremental costs required to implement AP need to be divided by the incremental benefit. The results of this analysis show that the net incremental benefit of the AP would be an annual increase between 4.4 and $9 \cdot 1 \mu \mathrm{g} / \mathrm{l}$ urinary iodine. This would lead to an incremental annual decline in goitre between 2.3 and $6.4 \%$. These are the net benefits over and above the increase already occurring because of SP. The costs divided by the incremental benefits would provide the incremental cost-effectiveness of AP.

As in any analysis based on published data, there are several limitations. The estimation of the trends is based on only nine localities and on two or three surveys per locality, with the consequence that the results might not be generalizable and that the average annual changes based on a few points in time may hide substantial fluctuations. This has inevitable consequences on the exact estimation of the annual changes and on the certainty that such changes will continue at a stable rate.

Nonetheless, the fact that the changes in the nine localities coincide with the changes predicted by the quadratic model strengthen the causal inferences and the generalization of the results based on the nine localities. The increase of $1-2 \mu \mathrm{g}$ urinary iodine per $1 \%$ decline in goitre experienced by the nine localities is in line with the predictions based on the sixty

Table 5. Coefficients of the quadratic model in Fig. 1 (dependent variable: goitre prevalence)

\begin{tabular}{|c|c|c|c|c|c|}
\hline \multirow[b]{2}{*}{ Model } & \multicolumn{2}{|c|}{$\begin{array}{l}\text { Unstandardized } \\
\text { coefficients }\end{array}$} & \multirow{2}{*}{$\frac{\text { Standardized coefficient }}{\beta}$} & \multirow[b]{2}{*}{$t$} & \multirow[b]{2}{*}{ Significance } \\
\hline & $B$ & SE & & & \\
\hline (Constant) & $72 \cdot 012$ & $6 \cdot 795$ & & $10 \cdot 598$ & 0.000 \\
\hline Mean urinary iodine $(\mu \mathrm{g} / \mathrm{l})$ & -0.869 & 0.130 & -2.029 & -6.656 & 0.000 \\
\hline IODSQUAR & 0.003 & 0.001 & 1.399 & 4.573 & 0.000 \\
\hline Distance from the sea $(\mathrm{km})$ & 0.079 & 0.032 & 0.199 & $2 \cdot 490$ & 0.016 \\
\hline
\end{tabular}

IODSQUAR, urinary iodine squared. 


\begin{tabular}{|c|c|c|c|c|c|c|c|c|c|}
\hline & \multicolumn{9}{|c|}{ Urinary iodine $(\mu \mathrm{g} / \mathrm{l})$} \\
\hline & $10 \cdot 00$ & $20 \cdot 00$ & $30 \cdot 00$ & $40 \cdot 00$ & $50 \cdot 00$ & $60 \cdot 00$ & $70 \cdot 00$ & $80 \cdot 00$ & $90 \cdot 00$ \\
\hline Expected goitre prevalence (\%) & 63.52 & 55.43 & $47 \cdot 74$ & $40 \cdot 45$ & 33.56 & $27 \cdot 07$ & 20.98 & $15 \cdot 29$ & $10 \cdot 00$ \\
\hline $\begin{array}{l}\text { Expected decline in goitre prevalence if urinary } \\
\text { iodine increases by } 10 \mu \mathrm{g} / \mathrm{l}(\%)\end{array}$ & -8.09 & -7.69 & -7.29 & -6.89 & -6.49 & -6.09 & -5.69 & -5.29 & -4.89 \\
\hline Change in $\%$ goitre per $\mu \mathrm{g}$ increase in urinary iodine & -0.809 & -0.769 & -0.729 & -0.689 & -0.649 & -0.609 & -0.569 & -0.529 & -0.489 \\
\hline $\begin{array}{l}\text { Increase in urine iodine for goitre to decline by } \\
1 \%(\mu \mathrm{g} / \mathrm{l})\end{array}$ & $1 \cdot 236$ & $1 \cdot 300$ & $1 \cdot 371$ & 1.4513 & $1 \cdot 5408$ & 1.642 & 1.757 & $1 \cdot 890$ & $2 \cdot 044$ \\
\hline
\end{tabular}

For further explanation, see p. 819.

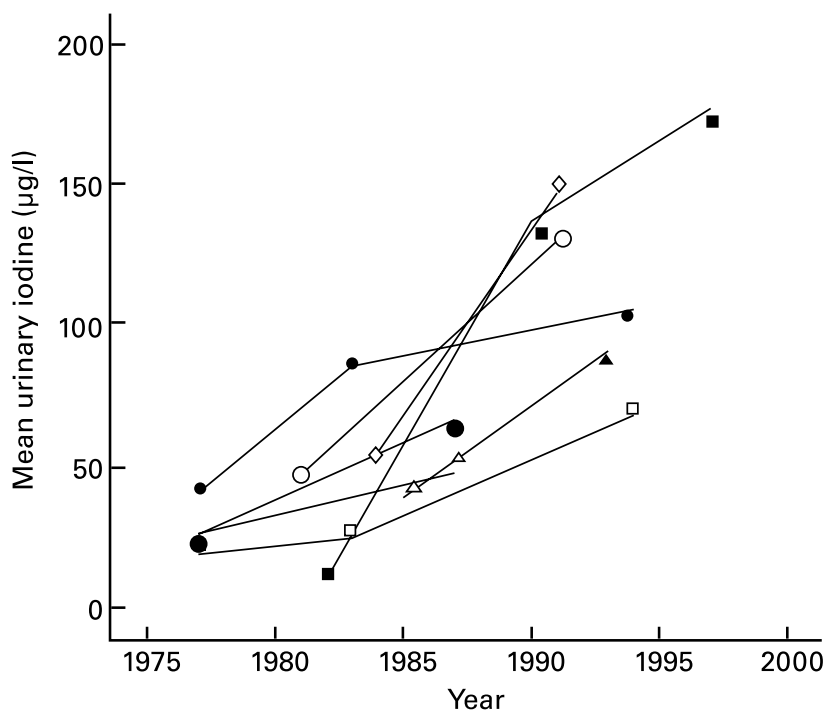

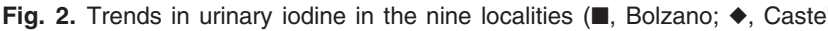
Umberto; $\diamond$, Garfagnana; $\square$, Maniaci; $\Delta$, Santangelo;, Sinagra; $\bullet$, Troina $\bigcirc$, Vagli; $\boldsymbol{\Lambda}$, Valtiberina).

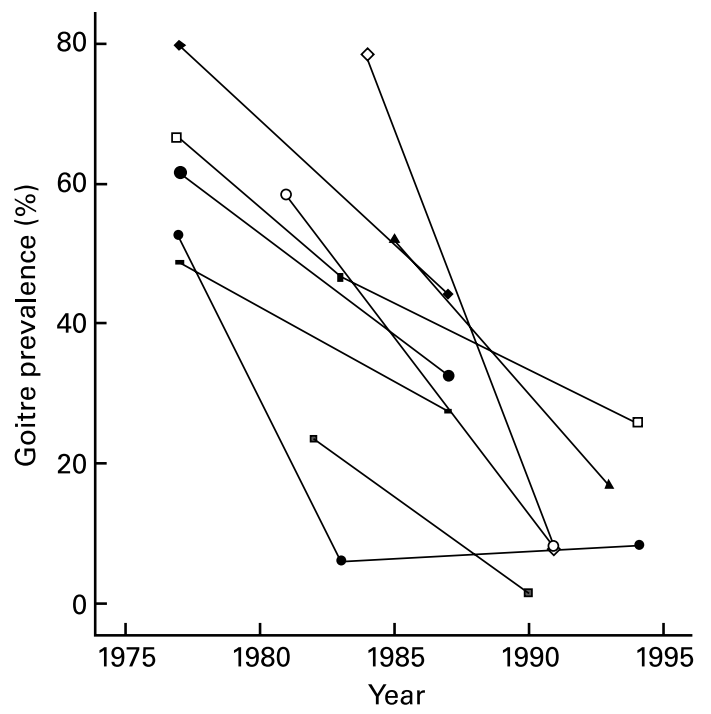

Fig. 3. Trends in goitre prevalence in the nine localities ( $\square$, Bolzano; Castel Umberto; $\diamond$, Garfagnana; $\square$, Maniaci; $\triangle$, Santangelo; $\bullet$, Sinagra; Troina; $\bigcirc$, Vagli; $\Delta$, Valtiberina). localities sampled cross-sectionally across the country. This strengthens the hypothesis that the data provided by the nine localities are unlikely to be very far off the mark in representing what has happened in the last few decades in the country. This is the best prediction we can get from available data and it is unlikely that community trials would provide very different results.

Another limitation of the analysis is the absence of information on how the SP might have worked. The only variables which may have influenced the iodine consumption in the localities and which were included in the model were distance from the sea, altitude and latitude. However, no information was available on the sources of iodine intake in these localities. Although dietary surveys have been carried out in Italy during the last few decades, they were not suitable for measuring trends in the consumption of iodine supplements. However, it is unlikely that increased consumption of fortified products has taken place in Italy in the last few decades with the exception of a few limited areas. As mentioned earlier, the proportion of fortified salt for human consumption is estimated to be less than $3 \%$. There is also no evidence that the iodine in dairy products has increased as the result of supplements given to dairy cattle.

Although the data analysed did not contain any information on the possible causes of SP, it is likely that this is the result of a spontaneous and gradual increase in consumption of products

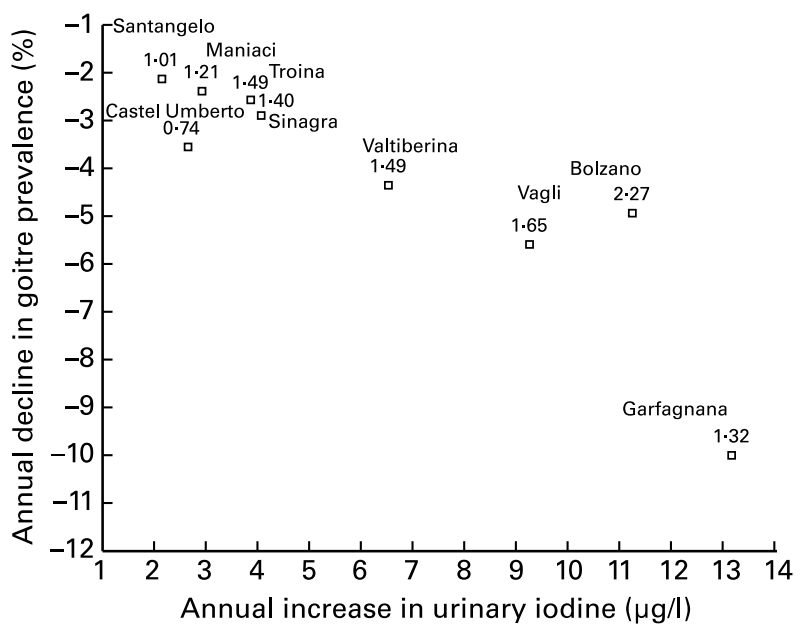

Fig. 4. Annual decline in goitre prevalence against annual increase in urinary iodine in the nine localities. Valtiberina, Vagli, Bolzano and Garfagnana had a higher annual increase in urinary iodine excretion because they had active prophylaxis. The numbers besides the localities represent the average increase in $\mu \mathrm{g}$ urinary iodine associated with $1 \%$ decline in the prevalence of goitre. 
containing iodine. Given the relative scarcity of iodine fortification carried out in Italy, it is likely that SP has been produced as the result of increased access to products coming from noniodine-deficient areas. These might have included food and nonfood items such as pharmaceutical products whose consumption increases with socioeconomic development. Therefore, the most likely mechanism of SP is an increased access to a variety of products and a lower reliance on products that are locally produced in iodine-deficient areas.

Although forecasts on the future of SP prophylaxis are difficult, the assumptions given earlier suggest that it is likely to continue. Even if the limitation of the data cannot ensure that SP will continue at the same pace, the likelihood that SP will decline is slim. If SP is the result of development, the only way that SP could decline is with declining development, which in the case of Italy is unlikely. The sustainability of SP is suggested by its being a natural phenomenon not requiring an active effort from local authorities and an efficient delivery system. Therefore, the probability that $\mathrm{SP}$ will continue is high, although the pace of goitre decline may not be the same as in the past. When goitre reaches lower prevalence rates, the amount of iodine required to decrease prevalence by $1 \%$ increases. Therefore, the rate of decline in the prevalence of goitre is likely to slow down in the future.

\section{References}

Aghini-Lombardi F \& Antonangeli L (1998) Legislazione sulla iodoprofilassi in Italia (Iodine prophylaxis legislation in Italy). Ann Ist Sup Sanita 34, 363-366.

Aghini-Lombardi F, Antonangeli L \& Vitti P (1998) Epidemiologia del gozzo endemico in Italia (Epidemiology of endemic goitre in Italy). Ann Ist Super Sanita 34, 311-314.
Aghini-Lombardi F, Pinchera A, Antonangeli L, et al. (1995) Mild iodine deficiency during fetal/neonatal life and neuropsychological impairment in Tuscany. J Endocrinol Invest 18, 57-62.

Antonangeli L, Leoli F, Maccherii F \& Aghini-Lombardi F (1998) Effetti della iodoprofilassi su base volontaria sul volume tiroideo della popolazione giovanile in Val Tiberina (Effects of iodine prophylaxis on a voluntary basis on the thyroid volume of a young population in Val Tiberina). Ann Ist Super Sanita 34, 399-402.

Delange F, Van Onderbergen A, Shabana W, Vandemeulebroucke E, Vertongen F, Gnat D \& Dramaix M (2000) Silent iodine prophylaxis in Western Europe only partly corrects iodine deficiency; the case of Belgium. Eur J Endocrinol 143, 189-196.

Franzellin F (1998) Esperienze di iodoprofilassi in provincia di Bolzano (Experience of iodine prophylaxis in the province of Bolzano, Alto Adige). Ann Ist Sup Sanita 34, 377-381.

Istituto Nazionale di Statistica (1990) Comuni, Comunita' Montane, Regioni Agrarie al 31 Dicembre 1998. Roma, Italy: Istituto Nazionale di Statistica.

Maccherini D, Antonangeli L, Leoli F, Rago T, Vitti P \& Aghini-Lombardi F (1998) Epidemiologia del gozzo endemico in Toscana (Epidemiology of endemic goitre in Tuscany). Ann Ist Super Sanita 34, 395-397.

Regalbuto C, Salamone S, La Rosa GL, Calaciura F, Buscema M \& Vigneri C (1998) Carenza iodica ed esperienza di iodoprofilassi in Sicilia (Iodine deficiency and experience of iodine prophylaxis in Sicily). Ann Ist Sup Sanita 34, 429-436.

Regalbuto C, Squatrito S, La Rosa GL, Cercabene G, Ippolito A, Tita P, Salamone S \& Vigneri R (1996) Longitudinal study on goiter prevalence and goitrogen factors in northeastern Sicily. $J$ Endocrinol Invest 19, 638-645.

Report of the Subcommittee for the Study of Endemic Goitre and Iodine Deficiency of the European Thyroid Association (1985) Goitre and iodine deficiency in Europe. Lancet 1, 1289-1293.

Vermiglio F, Finocchiaro MD, Lo Presti VP, La Torre N, Nucifora M \& Trimarchi F (1989) Partial beneficial effects of the so called 'silent iodine prophylaxis' on iodine deficiency disorders (IDD) in Northeastern Sicily endemia. J Endocrinol Invest 12, 123-126. 